\title{
Building a non-homogeneous environment for high effective cooling in the face of deep mines
}

\section{Xian Li}

Linyi University

Houli Fu ( $\sim$ fuhouli@lyu.edu.cn )

Linyi University

\section{Research}

Keywords: mine face, cooling system, non-homogeneous environment, air cooler, effective air-cooling space

Posted Date: April 9th, 2020

DOI: https://doi.org/10.21203/rs.3.rs-21819/v1

License: (1) This work is licensed under a Creative Commons Attribution 4.0 International License. Read Full License 


\title{
Building a non-homogeneous environment for high effective cooling in the face of deep mines
}

Xian Li and Houli Fu*

School of Civil Engineering and Architecture, Linyi University, Linyi 276000, China

*Corresponding email: fuhouli@lyu.edu.cn

\begin{abstract}
Heat exhaustion of mining environments can cause a great threat to human health. The existing cooling strategies for the mine face aim to cool the whole face. However, the area of effective air-cooling space for the face is small, and a great amount of energy for cooling is ineffective. Effective air-cooling space is a space occupied by the workers in the face. This study proposed to build a non-homogeneous environment for high effective cooling in the face. An inlet air cooler was laid out in the intake airway to cool the whole face to some extent, and the tracking air cooler was designed to track the worker who constantly moved to improve the thermal environment. The cooling load and air distribution for this cooling strategy were investigated. In addition, the airflow in the face was numerically solved to estimate the cooling effect. The results revealed that an average energy saving of approximately $35 \%$ could be achieved. The thermal environment of the effective air-cooling space within at least $10 \mathrm{~m}$ was significantly improved. This cooling strategy should be taken into account in mine cooling.
\end{abstract}

Keywords: mine face, cooling system, non-homogeneous environment, air cooler, effective air-cooling space 


\begin{tabular}{|c|c|c|c|}
\hline \multicolumn{4}{|c|}{ Nomenclature } \\
\hline$a$ & turbulent coefficient & $S$ & area of the face $\left(\mathrm{m}^{2}\right)$ \\
\hline$c_{p}$ & $\begin{array}{l}\text { specific heat at constant pressure } \\
(\mathrm{kJ} /(\mathrm{kg} \cdot \mathrm{K}))\end{array}$ & $T, t$ & temperture of airflow $\left({ }^{\circ} \mathrm{C}, \mathrm{K}\right)$ \\
\hline$d$ & $\begin{array}{l}\text { vertical distance between the tracking air } \\
\text { cooler and the worker }(\mathrm{m})\end{array}$ & $t_{\mathrm{gu}}$ & $\begin{array}{l}\text { initial temperature of the } \\
\text { surrounding rock }\left({ }^{\circ} \mathrm{C}\right)\end{array}$ \\
\hline$d_{0}$ & $\begin{array}{l}\text { equivalent diamater of outlet of the } \\
\text { tracking air cooler }(\mathrm{m})\end{array}$ & $\bar{t}$ & average air temperature $\left({ }^{\circ} \mathrm{C}\right)$ \\
\hline $\mathbf{g}$ & gravity acceleration $\left(\mathrm{m} / \mathrm{s}^{2}\right)$ & $\Delta t$ & temperature difference $\left({ }^{\circ} \mathrm{C}\right)$ \\
\hline$H$ & $\begin{array}{l}\text { cooling range of the tracking air cooler } \\
\text { (m) }\end{array}$ & $\mathbf{U}$ & air velocity $(\mathrm{m} / \mathrm{s})$ \\
\hline$i$ & enthalpy value of airflow $(\mathrm{kJ} / \mathrm{kg})$ & $U$ & perimeter $(\mathrm{m})$ \\
\hline$K_{\tau}$ & 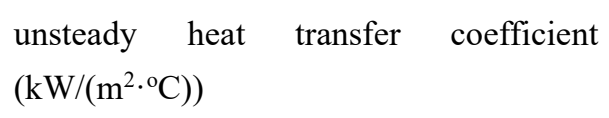 & $V$ & supply air volume $\left(\mathrm{m}^{3}\right)$ \\
\hline$L$ & length (m) & $v_{l}$ & $\begin{array}{l}\text { jet speed at the location of } \\
\text { worker }(\mathrm{m} / \mathrm{s})\end{array}$ \\
\hline$l$ & $\begin{array}{l}\text { distance between the tracking air cooler } \\
\text { and the worker }(\mathrm{m})\end{array}$ & Gre & ariable \\
\hline$M_{\mathrm{B}}$ & mass flow rate of airflow $(\mathrm{kg} / \mathrm{s})$ & $\kappa_{\text {eff }}$ & $\begin{array}{l}\text { effective air thermal } \\
\text { conductivity }(\mathrm{W} /(\mathrm{m} \cdot \mathrm{K}))\end{array}$ \\
\hline$M_{\mathrm{BT}}$ & $\begin{array}{l}\text { mass flow rate of airflow for the tracking } \\
\text { air cooler }(\mathrm{kg} / \mathrm{s})\end{array}$ & $\rho$ & air density $\left(\mathrm{kg} / \mathrm{m}^{3}\right)$ \\
\hline $\mathrm{n}$ & quantity of the tracking air cooler & $\tau$ & viscous stress tensor \\
\hline$p$ & air pressure $(\mathrm{Pa})$ & $\xi$ & correction factor \\
\hline$Q$ & cooling load $(\mathrm{kW})$ & $\varphi$ & relative humidity (\%) \\
\hline$S_{\mathrm{E}}$ & area of the effective air cooling space $\left(\mathrm{m}^{2}\right)$ & & \\
\hline
\end{tabular}

\section{Introduction}

Heat exhaustion of mining environments has caused increasing concern (Sasmito et al. 2015). With the decrease of mineral resources, the mining depth continuous increases (Crawford et al. 2019). The temperature of initial surrounding rocks rises with the mining depth (Du et al. 2013a; Yi et al. 2019). Meanwhile, the electromechanical equipment can also release a large amount of heat. These heat sources transfer heat to airflow in mining environments and the heat damage inevitably happens (Maurya et al. 2015). Heat exhaustion aggravates deterioration of the thermal environment of mines and then causes a great threat to human health (Su et al. 2009; Guo et al. 2014). Workers who work long time in the high 
temperature environment are susceptible to fatigue and heat illness (Katavoutas et al. 2016). The work efficiency then decreases and the accident is bound to happen more frequently (Armstrong and Lopez 2007; Kasap 2011). Thus, Mine cooling becomes increasing urgent.

Generally, there are two kinds of cooling methods for mines: non-artificial refrigeration method and artificial refrigeration method (Chatterjee et al. 2015; Bellas and Tassou 2005). For the non-artificial refrigeration method, the airflow temperature is lowered by increasing ventilation and heat discharge. However, this method is only suitable for places where the heat exhaustion is not serious. When the temperature of initial surrounding rocks is high enough, the artificial refrigeration method should be adopted (Ji et al. 2019). Artificial refrigeration is a method in which work is done to remove heat from one location to another by using manual methods (Waltrich et al. 2011). According to the type of secondary refrigerant, the artificial refrigeration system can be divided into central air conditioning cooling system, ice cooling system, and water cooling system (Wang et al. 2017; Chen et al. 2016). The secondary refrigerant is an intermediate cooling medium that transfers heat from a space to the refrigerant (Bao et al. 2014). The basic components of a critical water cooling system include a refrigeration unit, a chilled water pipeline, a cooling water pipeline, and an air cooler (Kusiak and Li 2010). The air cooler is a key component for cooling, whose type, layout and operating parameters have a significant impact on the effect of the cooling system.

The mine face is a long and narrow working space and has plenty of equipment and workers (Guo et al. 2010). Generally, the temperature of face is much higher than other places of mines, and thus it is the important region for cooling. There were mainly three layout modes of the air cooler for cooling the face, as shown in Fig. 1 (Guo and Chen 2013). When the air cooler was laid out in the intake airway (Fig. 1(a)), the cold airflow was transported to the face for a long distance, and a certain of cooling loss was inevitably produced. The temperature of airflow had been very high in the posterior region of the face because of the heat exchange between the airflow and the surrounding rocks. In order to achieve a benign cooling effect, more energy should be consumed. The air cooler which was laid out in the return airway (Fig. 1(b)) was used to cold the airflow there and had little effect on the face. As for the third layout mode, a quantity of smaller air coolers were uniformly laid out in the face. Because the smaller air coolers cooled the face immediately, this layout mode could save a certain energy and achieve a better cooling 
effect than other layout modes. However, the mine face was quite long and had plenty of heat sources, this cooling strategy also consumed a great amount of energy (Abdelaziz et al. 2011). The cooling load for a typical mine face can reach up to $300 \mathrm{~kW}$. Approximately $25 \%$ of the total energy consumption of mines originated from the mining cooling (Crawford et al. 2019; Du et al. 2013b).

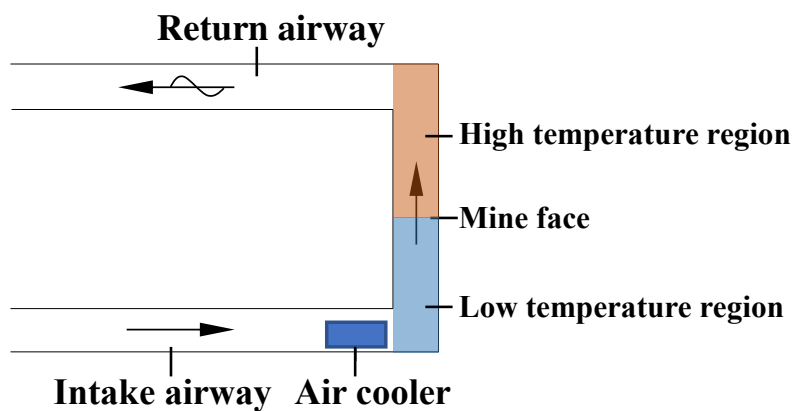

(a)

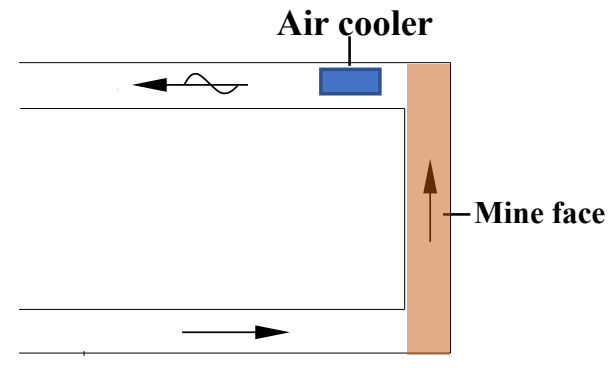

(b)

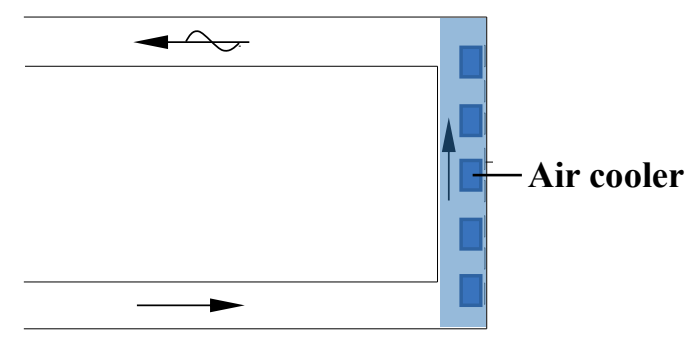

(c)

Fig. 1 Layout mode of the air cooler for mine cooling at various locations: (a) intake airway; (b) return airway; (c) mine face

The above review reveals that the existing cooling strategies aim to cool the whole face and build a homogeneous thermal environment. However, there are only a small area occupied by workers in the face, thus, a great amount of energy is ineffective. Until the present time, there is no study on a high effective cooling strategy focusing on the workers in the face. For cost-effective energy savings and obtaining benign thermal environment, a new cooling strategy of building non-homogeneous environment for high effective cooling in the mine face was proposed in this study. The concept of effective air-cooling space was put forward for the first time. A novel tracking air cooler was designed to track the worker who constantly moved in the face and improve the thermal environment of the effective air-cooling space. The cooling load and economic efficiency for this new cooling strategy were estimated. Numerical simulation of the airflow in the face was performed to compare the cooling effect 
between the new cooling strategy and the traditional cooling strategy.

\section{Principles for building the non-homogeneous environment in the face}

In this section, the basic principles for building the non-homogeneous environment are presented first, followed by cooling load calculation. The economic analysis for this cooling strategy is then addressed.

\subsection{Building the non-homogeneous environment and tracking air cooler}

To achieve high effective cooling to the workers in the face, the air cooler should focus on the effective air-cooling space and deprioritize the ineffective air-cooling space. Effective air-cooling space is a space occupied by the workers in the face. The effective air-cooling space may be a fixed space, for example, the location where the driver of the pump station is, or a constantly moving space, for example, the location where the shearer driver is. Whether fixed or moving workers, the occupied areas of them are equal. In contrast, ineffective air-cooling space is a space where no worker was. Because the mine face is long and narrow, the ineffective air-cooling space is much larger than the effective air-cooling space. Note that the space occupied by the equipment is also needed to be cooled for its safety. In this study, the space where workers occupied was as a representative of the effective air-cooling space.

Fig. 2 illustrates the basic principles for building non-homogeneous environment in the mine face. The system was composed of an air cooler in the intake airway, an inlet pipe of chilled water, a return pipe of cooling water, and a quantity of small tracking air coolers in the face. The chilled water was transported to the air cooler by the chilled water pipe and then the air cooler cooled the face. The tracking air cooler was used to cool the effective air-cooling space and improve the thermal environment for workers. When a worker entered the control range of a tracking air cooler, the air cooler began to work and blew cold air to the worker. Other air coolers did not work and the ineffective air-cooling space was ignored. When the worker moved, the air cooler constantly tracked him. Once the worker left the control range of the tracking air cooler and entered that of the next one, the last air cooler automatically stopped and the next one began to work, as shown in Fig. 3. Thus, the benign thermal environment for the worker could be guaranteed. The inlet air cooler was used to cool the whole face to some extent. It could prevent the 
excessive temperature difference between the effective air-cooling space and ineffective air-cooling space. Overheating in the ineffective air-cooling space might affect the human thermal comfort.

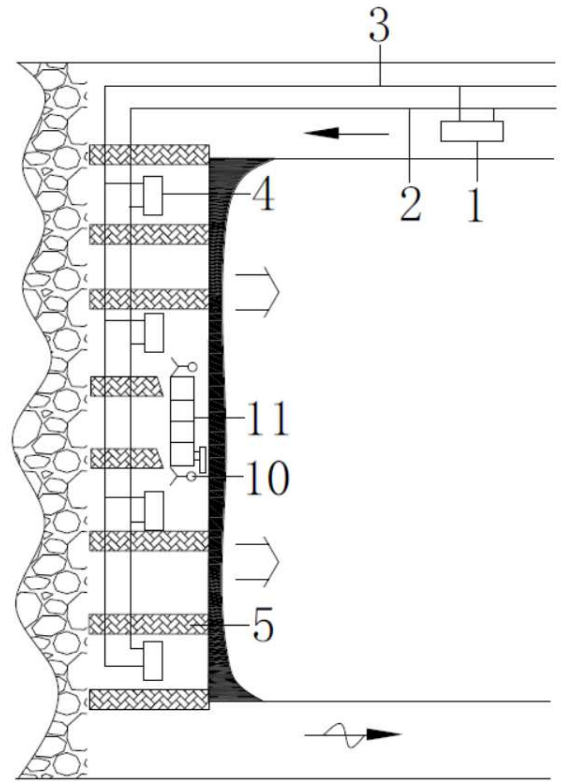

(a)

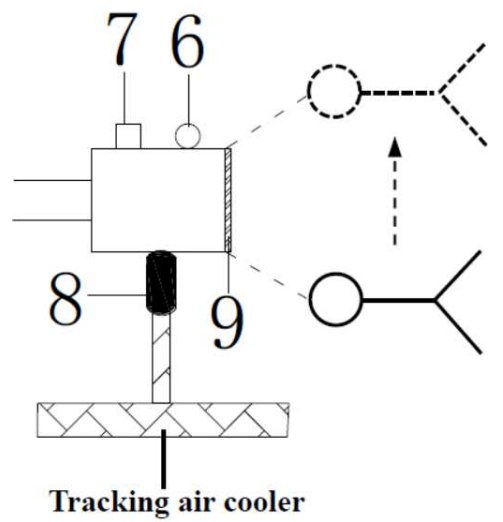

(b)

1. Inlet air cooler, 2. Inlet pipe of the chilled water, 3. Return pipe of the cooling water, 4. Tacking small air cooler, 5. Hydraulic support, 6. Infrared detector, 7. Controller, 8. Electric spindle, 9. Air door, 10. Worker, 11. Shearer

Fig. 2 Schematic diagram of building the non-homogeneous environment in the face: (a) layout mode of the inlet and tracking air coolers; (b) constitution of the tracking air cooler

The difficulty of building non-homogeneous environment was how to guarantee the benign thermal environment for the constantly moving workers. For this purpose, the tracking small air cooler was designed. The tracking object was the workers in the face. Each air cooler controlled a certain area and the areas of two adjacent air coolers were mutually related, as shown in Fig. 3. The tracking small air cooler could be placed between the two columns of the hydraulic support in the face.

The tracking air cooler was composed of an infrared detector, a controller, an electric spindle, and an air door (Fig. 2). When a worker arrived at the control range of the tracking air cooler, the infrared detector sensed worker's signal and transmitted the signal to the controller. Then the controller opened the air door and the air cooler blew the cold airflow to the effective air-cooling space. When the worker 
moved, the electric spindle continuously rotated and tracked with him according to the infrared signal so that the air door was kept facing to the worker. When the worker left the control range of the air cooler, the air door and electric spindle closed and the next air cooler began to work (Fig. 3). Because the tacking air cooler accurately cooled the effective air-cooling space and deprioritized the ineffective air-cooling space, this cooling strategy could save a great amount of energy.

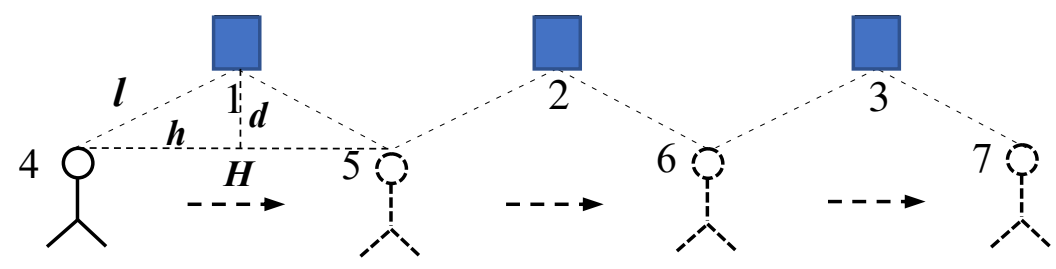

Fig. 3 Schematic diagram of cooling process of the tracking air cooler

\subsection{Cooling load calculation}

The cooling load for building the non-homogeneous environment in the face was composed of two parts: the cooling load for the background airflow in the face and that for the effective air-cooling space. Thus, the total cooling load can be summarized as:

$$
Q=Q_{1}+Q_{2}
$$

where, $Q$ is the toal cooling load (kW), $Q_{1}$ is the cooling load for the background airflow $(\mathrm{kW}), Q_{2}$ is the cooling load for the effective air-cooling space $(\mathrm{kW}) . Q_{1}$ was estimated as:

$$
Q_{1}=M_{\mathrm{B}}\left(i_{1}-i_{2}\right)
$$

where, $M_{\mathrm{B}}$ is the mass flow rate of the airflow in the face $(\mathrm{kg} / \mathrm{s}), i_{1}$ is the enthalpy value of the inlet airflow before cooling by the inlet air cooler $(\mathrm{kJ} / \mathrm{kg}), i_{2}$ is the enthalpy value of the inlet airflow after cooling by the inlet air cooler $(\mathrm{kJ} / \mathrm{kg}) . i$ was estimated as (Hartman et al. 2012): 


$$
i=\mathrm{c}_{0}(\varphi / \mathrm{B})+\left[1.005+\mathrm{c}_{1}(\varphi / \mathrm{B})\right] t_{\mathrm{in}}+\left[\mathrm{c}_{2}(\varphi / \mathrm{B})\right] t_{\mathrm{in}}{ }^{2}
$$

where, $t_{\text {in }}$ is the temperture of inlet airflow in the face $\left({ }^{\circ} \mathrm{C}\right), \varphi$ is the relative humidity $(\%), \mathrm{c}_{0}, \mathrm{c}_{1} 、 \mathrm{c}_{2}$ are constant coefficients. $t_{\text {in }}$ was estimated as:

$$
t_{\text {in }}=t_{\text {out }} e^{R \mathrm{~K}(\Phi)}-\frac{e^{R \mathrm{~K}(\Phi)}-1}{R}\left(T+\frac{\sum Q_{M}}{M_{\mathrm{B}} c_{p}}\right)
$$

where, $R=\frac{K_{\tau} U L}{M_{\mathrm{B}} c_{p}}+\frac{\mathrm{N}_{\mathrm{y}}}{\mathrm{B}-\mathrm{P}_{\mathrm{m}}} \mathrm{V} \varphi, \mathrm{V} \varphi=\varphi_{\text {out }}-\varphi_{\text {in }}, \mathrm{E}=\frac{\mathrm{N}_{\mathrm{y}}}{\mathrm{B}-\mathrm{P}_{\mathrm{m}}}, T=R t_{\mathrm{gu}}-\frac{\mathrm{N}_{\mathrm{y}} \varepsilon \mathrm{V} \varphi}{\mathrm{B}-\mathrm{P}_{\mathrm{m}}}, t_{\text {out }}$ is the tempeture of outlet airflow in the face $\left({ }^{\circ} \mathrm{C}\right), K_{\tau}$ is the unsteady heat transfer coefficient between surrounding rocks and airflow $\left(\mathrm{kW} /\left(\mathrm{m}^{2 .{ }^{\circ}} \mathrm{C}\right)\right), c_{p}$ is the specific heat at constant pressure of air $(\mathrm{kJ} /(\mathrm{kg} \cdot \mathrm{K}))$, $L$ and $U$ are the length and perimeter of the face $(\mathrm{m}), t_{\mathrm{gu}}$ is the initial temperature of the surrounding rock $\left({ }^{\circ} \mathrm{C}\right), \varphi_{\text {in }}$ and $\varphi_{\text {out }}$ are the reletive humidities of the inlet and outlet airflow in the face (\%), B, $\mathrm{N}_{\mathrm{y}}$, $\mathrm{P}_{\mathrm{m}}, K(\Phi)$ and $\varepsilon^{\prime}$ are constant coefficients.

$Q_{2}$ was estimated by the ratio of the area of effective air-cooling space to that of the face:

$$
Q_{2}=\xi\left(Q_{3}-Q_{1}\right) \frac{S_{\mathrm{E}}}{S}
$$

where, $S_{\mathrm{E}}$ is the area of the effective air cooling space $\left(\mathrm{m}^{2}\right), S$ is the area of the face, $\left(\mathrm{m}^{2}\right), \xi$ is the correction factor, $Q_{3}$ is the cooling load for cooling the whole face (kW).

Accroding to Eqs. (1), (2) and (5), the cooling load for building the non-homogeneous environment was summarized as:

$$
Q=\frac{M_{\mathrm{B}}}{S}\left[S\left(i_{1}-i_{2}\right)+S_{\mathrm{E}} \xi\left(i_{2}-i_{3}\right)\right]
$$


where, $i_{3}$ is the the enthalpy value of the inlet airflow for cooling the whole face $(\mathrm{kJ} / \mathrm{kg})$.

\subsection{Case study and economic analysis}

In this section, a fully mechanized coal face was used as a case to eatimated the cooling load for building the non-homogeneous environment. The length and width of the face were $120 \mathrm{~m}$ and $2.5 \mathrm{~m}$, respectively. The average perimeter of the section was $10 \mathrm{~m}$. The average rock temperature was $36{ }^{\circ} \mathrm{C}$ and the unstable heat transfer coefficient of the surrounding rock was $3.856 \times 10^{-3} \mathrm{~kW} /\left(\mathrm{m}^{2} \cdot{ }^{\circ} \mathrm{C}\right)$. The air volume of the face was $350 \mathrm{~m}^{3} / \mathrm{min}$ and the air density was $1.221 \mathrm{~kg} / \mathrm{m}^{3}$. The average static pressure of air was $1.12 \times 10^{5} \mathrm{~Pa}$. The temperature and relative humidity of the inlet airflow before cooling were 27 ${ }^{\circ} \mathrm{C}$ and $95 \%$ and those of the outlet airflow were $32{ }^{\circ} \mathrm{C}$ and $98 \%$, respectively. The total heat dissipation of various absolute heat sources in the face was approximately $100 \mathrm{~kW}$.

In the mine face, two workers drived the shearer to move back and forth, and four hydraulic support workers pushed the support forward. There were 11 workers located in the vicinity of the machine and at the end of two roadways and their working positions were relatively fixed. The body width of the worker and the average distance between the tracking air cooler and the worker were assumed to be 0.5 $\mathrm{m}$ and $5 \mathrm{~m}$, respectively, according to Eq. (10) in third section. The area of effective air-cooling space was then estimated as $42.5 \mathrm{~m}^{2}$, which was much less than that of the face $\left(300 \mathrm{~m}^{2}\right)$

The temperature and relative humidity of the outlet airflow in the face after cooling were set as $26{ }^{\circ} \mathrm{C}$ and $98 \%$, respectively, based on the Coal mine safety regulation in China (Homer 2009). According to Eq. (4), the temperature and relative humidity of the inlet airflow were estimated as $17.75{ }^{\circ} \mathrm{C}$ and $100 \%$, respectively. Thus, the cooling load for cooling the whole face was $227.7 \mathrm{~kW}$.

For building the non-homogeneous environment, the higher the temperature of background airflow, the lower the cooling load. However, in order to prevent the excessive temperature difference between the effective and the ineffective air-cooling spaces, the outlet temperature and relative humidity of the background airflow were set as $29{ }^{\circ} \mathrm{C}$ and $100 \%$, respectively. According to Eq. (2), the cooling load of 
the inlet air cooler $\left(Q_{1}\right)$ was $98.31 \mathrm{~kW}$. The value of $\xi$ was set as 1.5 . According to Eq. (5), the cooling load of the tracking air coolers $\left(Q_{2}\right)$ was estimated as $50.45 \mathrm{~kW}$. Thus, the total cooling load for building the non-homogeneous environment was approximately $149 \mathrm{~kW}$, which was only $65 \%$ of that for cooling the whole face. Thus, this new cooling strategy could save approximately $35 \%$ of energy compared to the traditional cooling strategy and had great potentiality in energy saving.

\section{Air distribution for building the non-homogeneous environment}

In this section, to obtain benign thermal environment, the air distribution for building the nonhomogeneous environment was investigated. The cooling range, quantity, and supply air volume of the tracking air cooler were determined by the heat balance equation.

As shown in Fig. 3, the heat balance equation between the outlet of the tracking air cooler and the worker was established as (Hartman et al. 2012):

$$
M_{\mathrm{BT}}\left(i_{\mathrm{T} 2}-i_{\mathrm{T} 1}\right)=K_{\tau} U l\left(t_{\mathrm{gu}}-\bar{t}\right)+\frac{\sum Q_{\mathrm{M}}}{L} l
$$

where, $M_{\mathrm{BT}}$ is the mass flow rate of the airflow for the tracking air cooler $(\mathrm{kg} / \mathrm{s}), i_{\mathrm{T} 1}$ is the enthalpy value of the outlet airflow for the tracking air cooler $(\mathrm{kJ} / \mathrm{kg}), i_{\mathrm{T} 2}$ is the enthalpy value of the airflow at the location of the worker $(\mathrm{kJ} / \mathrm{kg}), l$ is the distance between the tracking air cooler and the worker $(\mathrm{m})$, $\sum Q_{M}$ is the total heat dissipating capacity for various heat sources in the face $(\mathrm{kW}), \bar{t}$ is the average air temperature between the outlet of the tracking air cooler and the worker $\left({ }^{\circ} \mathrm{C}\right)$. Based on Eq. $(7), l$ was estimated as:

$$
l=\frac{M_{\mathrm{BT}}\left(i_{\mathrm{T} 2}-i_{\mathrm{T} 1}\right) L}{K_{\tau} U L\left(t_{\mathrm{gu}}-\bar{t}\right)+\sum Q_{M}}
$$

The cooling range of the tracking air cooler could be calculated by $l$ and the vertical distance between 
the tracking air cooler and the worker:

$$
H=2 h=2 \sqrt{\frac{\left(M_{\mathrm{B}} L\right)^{2}\left(i_{\mathrm{T} 2}-i_{\mathrm{T} 1}\right)^{2}}{\left[\left(K_{\tau} U L\right)\left(t_{\mathrm{gu}}-\bar{t}\right)+\sum Q_{M}\right]^{2}}-d^{2}}
$$

where, $H$ is the cooling range of the tracking air cooler (m), $d$ is the vertical distance between the tracking air cooler and the worker (m).

After the cooling range of the tracking air cooler was determined, the quantity of tracking air cooler in the face was estimated as:

$$
n=\frac{L}{2 \sqrt{\left[\frac{M_{\mathrm{B}} L\left(i_{\mathrm{T} 2}-i_{\mathrm{T} 1}\right)}{\left(K_{\tau} U L\right)\left(t_{g u}-\bar{t}\right)+\sum Q_{\mathrm{M}}}\right]^{2}-d^{2}}}
$$

However, the estimated value of $n$ from Eq. (10) might not be a integer, the quantity of tracking air cooler was futher estimated as:

$$
n=\left\{\begin{array}{l}
\frac{L}{2 h}, \text { when } n \text { is a integer } \\
{\left[\frac{L}{2 h}\right]+1, \text { when } n \text { is a non-integer }}
\end{array}\right.
$$

The supply air volume of each tracking air cooler was estimated as (Hartman et al. 2012):

$$
V=\frac{S_{\mathrm{E}} \sum Q_{\mathrm{M}}}{S c_{p} \rho \Delta t}
$$

where, $V$ is the supply air volume of the tracking air cooler $\left(\mathrm{m}^{3} / \mathrm{s}\right), \Delta t$ is the temperature difference of 
airflow between the outlet of the tracking air cooler and the worker $\left({ }^{\circ} \mathrm{C}\right)$.

The blowing form of airflow for the air cooler could be approximately treated as a free jet. The jet speed at the location of the worker was estimated as:

$$
v_{l}=\frac{0.48 \frac{\mathrm{V}}{\mathrm{S}}}{\frac{a l}{d_{0}}+0.147}
$$

where, $v_{l}$ is the jet speed at the location of the worker $(\mathrm{m} / \mathrm{s}), d_{0}$ is the equivalent diamater of outlet of the tracking air cooler (m), $a$ is the turbulent coefficient of outlet airflow for the tracking air cooler.

\section{Numerical simulation of airflow for the non-homogeneous environment}

\subsection{Geometric model and boundary conditions}

To estimate the cooling effect of the new cooling strategy, computational fluid dynamics (CFD) simulations of the airflow in the mine face were performed. For simplicity, this study only conducted the case when the worker was face to the tracking air cooler and the air cooler did not rotated. Other assumptions are as follows:

(a) Two-dimensional space.

(b) Airflow field of the face is uniformly distributed in the vertical direction.

(c) Irregularity of the mining wall has no impact on airflow.

According to an actual fully mechanized coal face, the geometric model shown in Fig. 4 was created. The length and width of the intake and return airways were both $70 \mathrm{~m}$ and $4 \mathrm{~m}$ and those of the mine face were $250 \mathrm{~m}$ and $5 \mathrm{~m}$, respectively. The dimensions of the shearer were $10 \times 1.5 \mathrm{~m}$. The vertical distance of the inlet air cooler from the mine face was $20 \mathrm{~m}$. Ten tracking air coolers were equidistantly distributed in the mine face, according to Eq. (10). The distance between two adjacent tracking air coolers was $25 \mathrm{~m}$. For simplicity, other electromechanical equipment was not considered. 
Quadrilateral grid cells were generated by an integrated computer engineering and manufacturing code (ICEM, version 18.0.0) for CFD. Totally 100 thousand grids were created and the average grid size was $3.5 \mathrm{~cm}$. To capture the near-wall effect, the grids near the mine face walls and the shearer were refined. All the values of $\mathrm{y}^{+}$of the first near-wall grids were less than five. Three different average grid sizes were tested for grid-independence. The comparison results of flow simulations from the three grid sizes showed no significant difference.

$250 \mathrm{~m}$

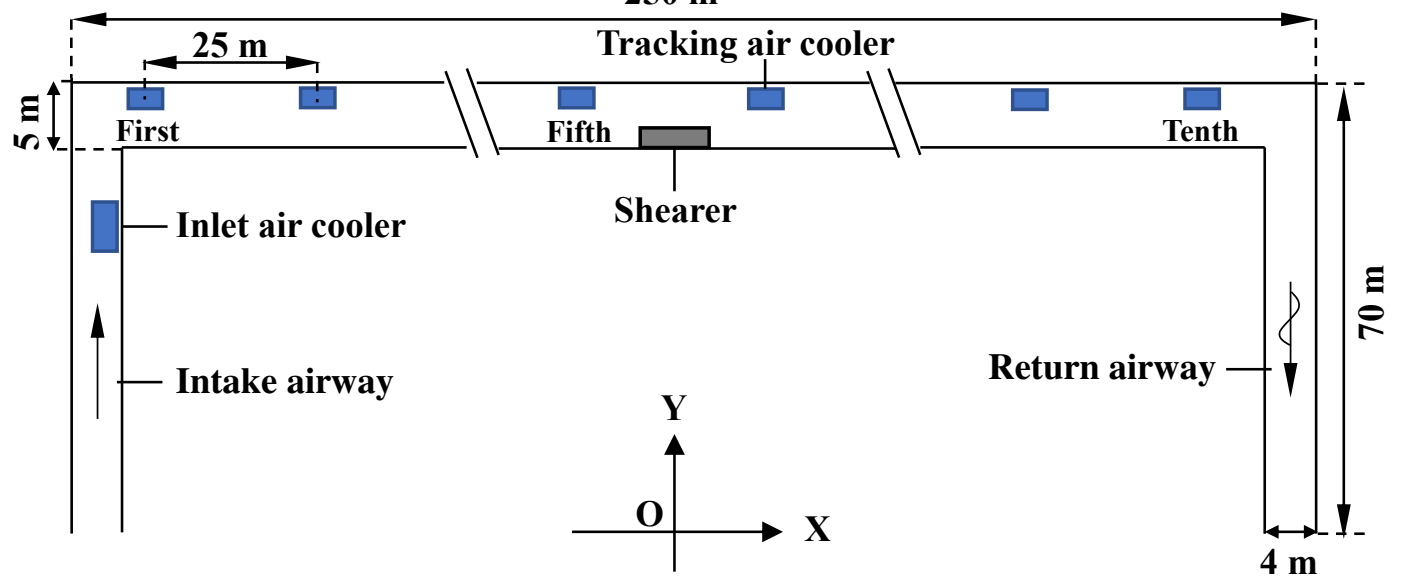

Fig. 4 Geometric model of the mine face for CFD simulations

To model the airflow in the mine face, the governing equations of fluid flow must be solved. The conservation equations for mass, momentum, and energy are summarized as:

$$
\begin{gathered}
\nabla \cdot \rho \mathbf{U}=0 \\
\nabla \cdot \rho \mathbf{U U}=-\nabla p+\nabla \cdot \tau+\rho \mathbf{g} \\
\nabla \cdot\left(\rho c_{p} \mathbf{U} T\right)=\nabla \cdot\left(\kappa_{\text {eff }}+\frac{c_{p} \mu_{t}}{\operatorname{Pr}_{t}}\right) \nabla T
\end{gathered}
$$

where, $\rho$ is the air density $\left(\mathrm{kg} / \mathrm{m}^{3}\right), \mathbf{U}$ is the air velocity $(\mathrm{m} / \mathrm{s}), p$ is the air pressure $(\mathrm{Pa}), \tau$ is the viscous stress tensor, $\mathbf{g}$ is gravity acceleration $\left(\mathrm{m} / \mathrm{s}^{2}\right), \kappa_{\text {eff }}$ is the effective air thermal conductivity $(\mathrm{W} /(\mathrm{m} \cdot \mathrm{K})), T$ is the air temperature $(\mathrm{K})$, and $\operatorname{Pr}_{t}$ is the turbulent Prandtl number. 
The airflow inside the mine face was turbulent, and the re-normalization group (RNG) $k$ - $\varepsilon$ model was adopted for turbulence modeling. The boundary conditions of temperature, heat flux, and air speed are shown in Table 1. Because the temperature of the mining wall was higher than that of the airflow, the wall dissipated heat to the airflow. The temperature and air speed of airflow for the tracking and inlet air coolers were estimated by the equations in the second and third sections.

Table 1 Boundary conditions for CFD simulations

\begin{tabular}{llll}
\hline Item & Temperature $\left({ }^{\circ} \mathrm{C}\right)$ & Heat flux $\left(\mathrm{W} / \mathrm{m}^{2}\right)$ & Air speed $(\mathrm{m} / \mathrm{s})$ \\
\hline Inlet airflow & 32 & - & 1.00 \\
Wall of intake airway & 34 & 200 & - \\
Wall of return airway & 35 & 400 & - \\
Coal wall & 35 & 600 & - \\
Goaf wall & 36 & 500 & - \\
Shearer wall & 50 & 800 & 1.50 \\
Inlet air cooler & 25 & - & 2.34 \\
Tracking air cooler & 22 & - & \\
\hline
\end{tabular}

All the variables were discretized using the second-order upwind scheme. Each simulation required approximately two thousand iterations for convergence tolerance of 1.0E-6 for all variables. The Fluent software program (version 18.0.0) was adopted to solve the governing equations.

\subsection{Numerical results}

To validate the cooling effect of the new cooling strategy, the temperature distribution of airflow cooled only by the inlet air cooler was compared with that by both the inlet and tracking air coolers.

Fig. 5 present the temperature distribution of airflow in the mine face cooled only by the inlet air cooler. The airflow temperature increased from $30.3{ }^{\circ} \mathrm{C}$ at the inlet to $31.6{ }^{\circ} \mathrm{C}$ at the outlet of the face, as shown 
in Fig. 6. In the vicinity of the shearer, the temperature rapidly increased from $30.8^{\circ} \mathrm{C}$ to $31.5^{\circ} \mathrm{C}$ within the range of $15 \mathrm{~m}$. Although the value of airflow temperature decreased approximately $2{ }^{\circ} \mathrm{C}$, compared to that before cooling, it was still quite high. The airflow temperature should be further reduced.

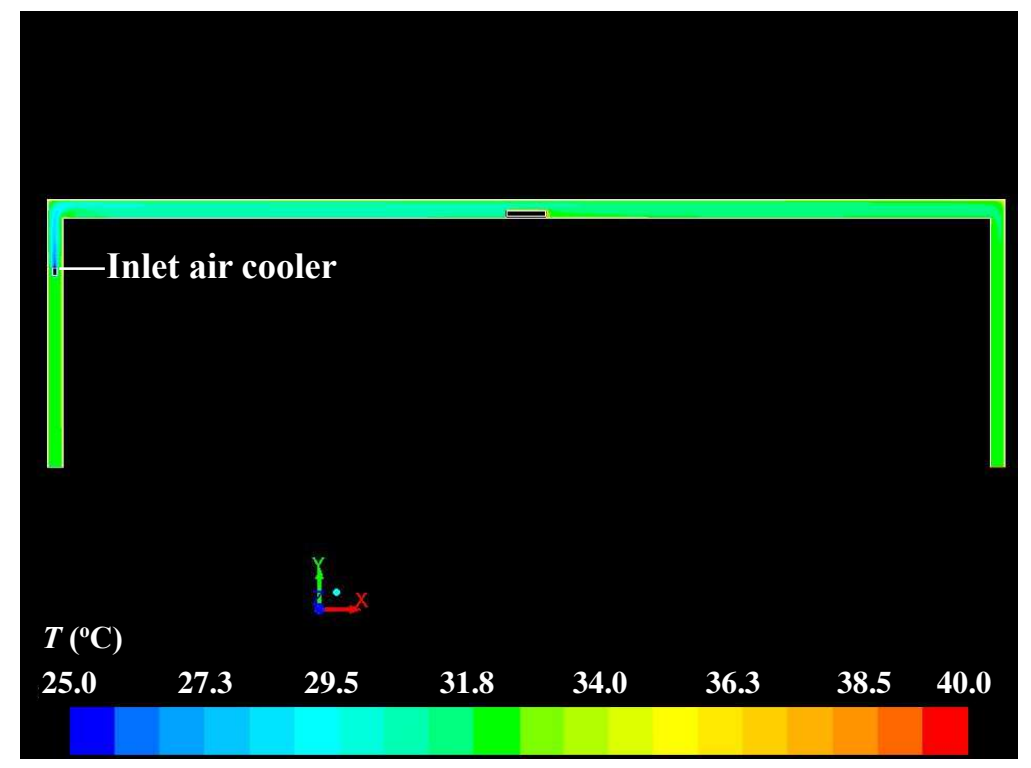

(a)

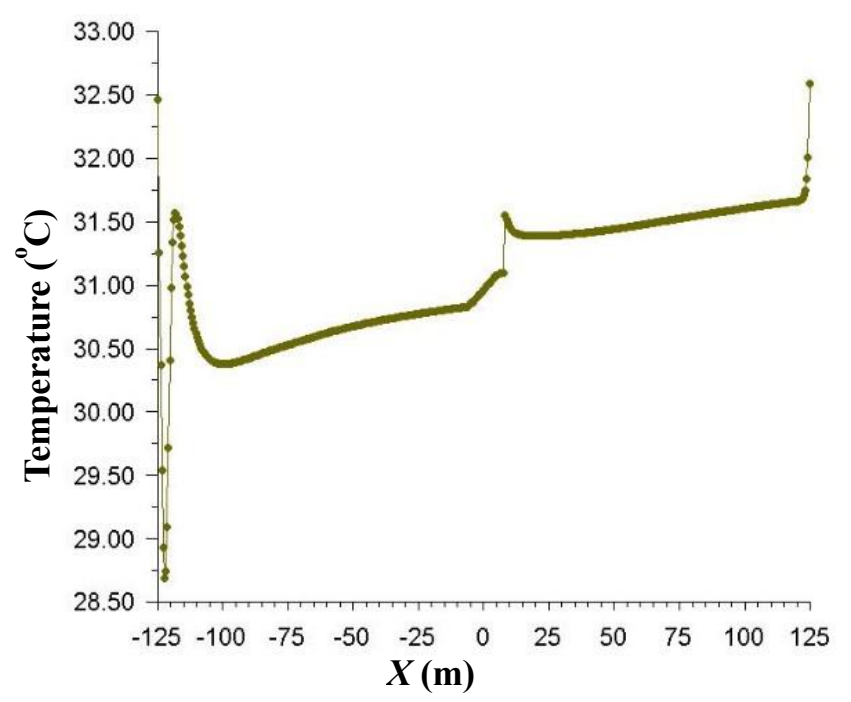

(b)

Fig. 5 Temperature distribution of airflow in the face cooled only by the inlet air cooler: (a) temperature contour; (b) variation of the temperature with the $X$ axis

Figs. 6 to 8 compares the temperature distribution of airflow in the mine face when the worker located in the control range of different tracking air coolers. Fig. 6(b) shows the airflow temperature versus the displacement of the mine face when the worker located in the control range of the first tracking air cooler. 
The airflow temperature increased from $24.8^{\circ} \mathrm{C}$ to $28.5^{\circ} \mathrm{C}$ within the control range of $15 \mathrm{~m}$. The average temperature decreased approximately $4.5^{\circ} \mathrm{C}$ as compared with that only by the inlet air cooler. Thus, the thermal environment of the effective air-cooling space was significantly improved.

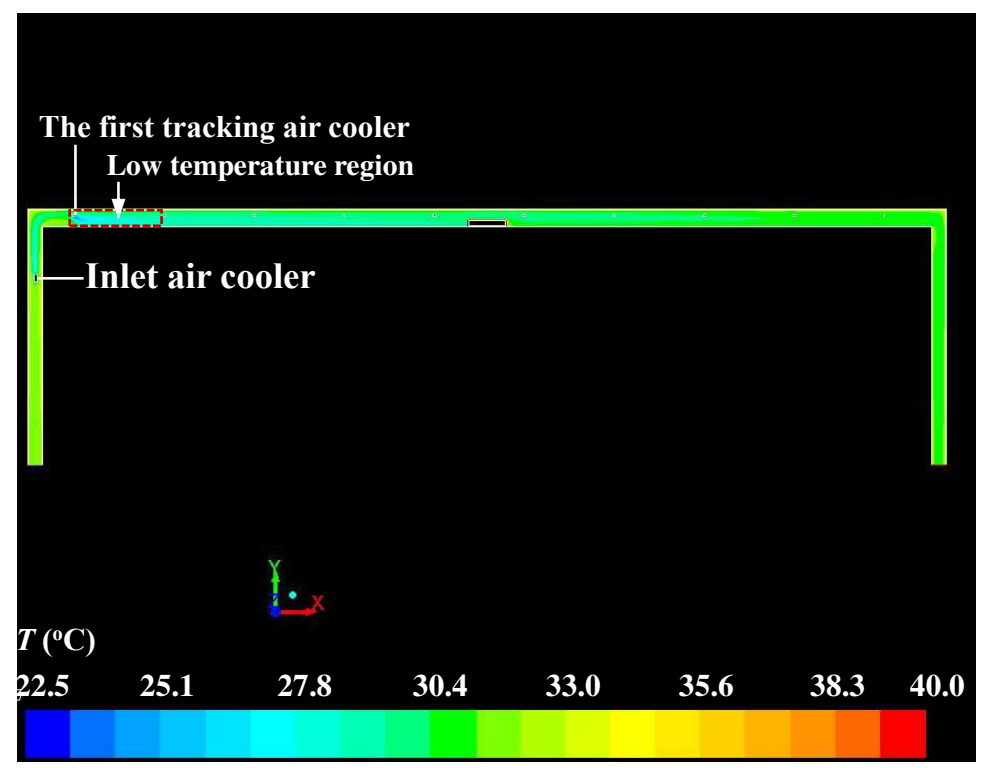

(a)

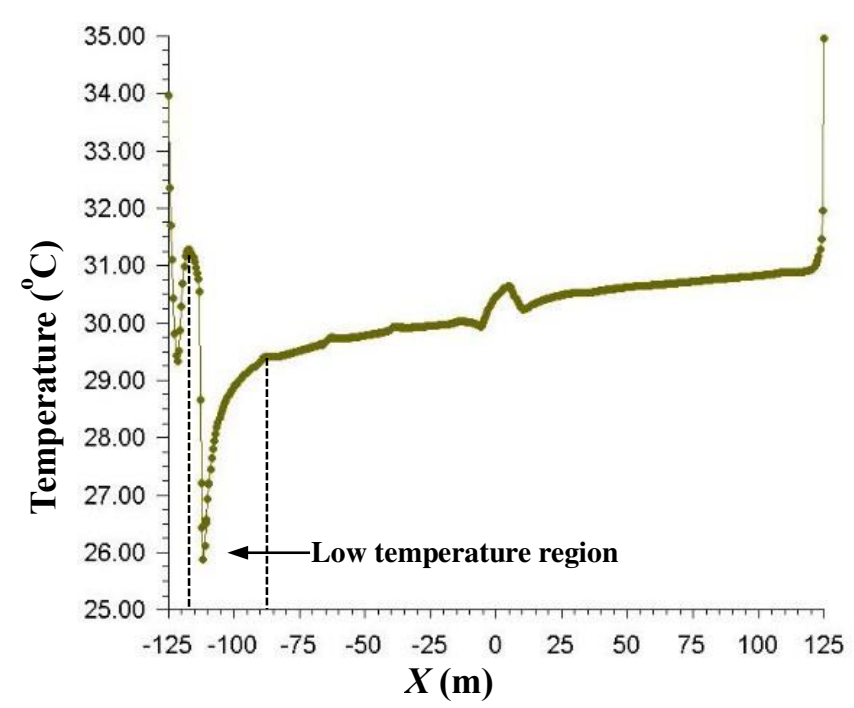

(b)

Fig. 6 Temperature distribution of airflow in the face when the worker was located in the control range of the first tracking air cooler: (a) temperature contour; (b) variation of the temperature with the $X$ axis

When the worker entered the control range of the fifth tracking air cooler (Fig. 7), the airflow temperature increased from $24.5^{\circ} \mathrm{C}$ to $28^{\circ} \mathrm{C}$ within the control range of $10 \mathrm{~m}$. Because the fifth tracking air cooler was near the shearer, the high temperature of shearer wall has an impact on the cooling effect 
of the air cooler. Thus, the airflow temperature suddenly increased to $30{ }^{\circ} \mathrm{C}$ within the next $5 \mathrm{~m}$. The thermal environment of the effective air-cooling space within the control range of $10 \mathrm{~m}$ was significantly improved. Similarly, when the tenth tracking air cooler worked (Fig. 8), the airflow temperature increased from 24.8 to $30{ }^{\circ} \mathrm{C}$ within the control range $15 \mathrm{~m}$. The value of the airflow temperature at the outlet of the face was higher than other places. This was mainly because heat was aggregated at the return airflow corner and the temperature therein was much higher than that of the cold airflow. The results indicated that the airflow temperature near the shearer and at the outlet of the face should be further decreased to improve the thermal environment.

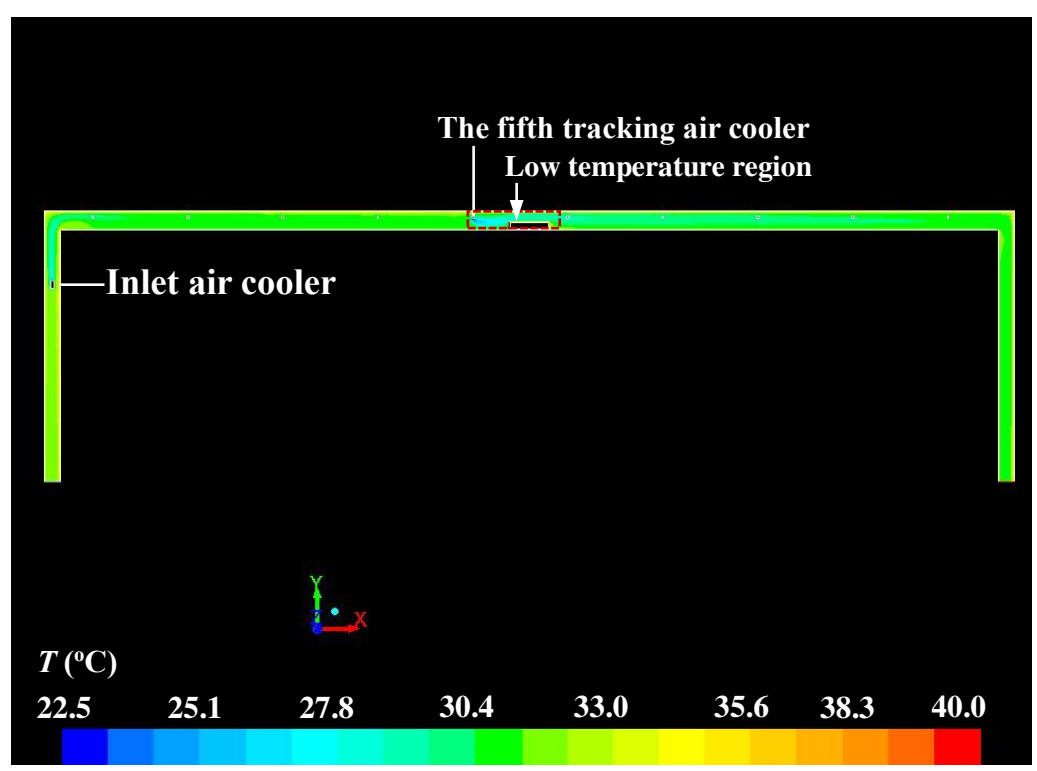

(a)

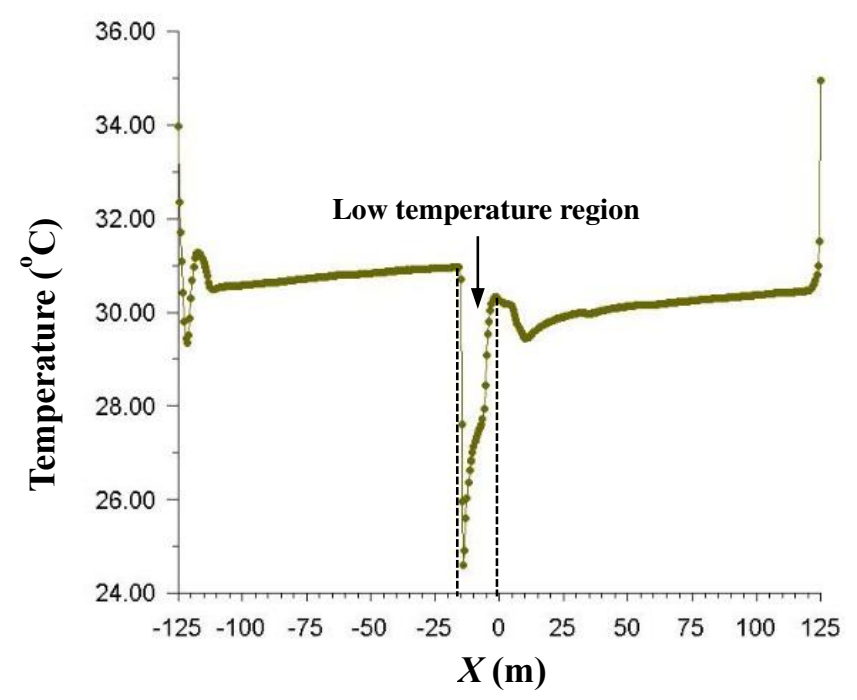

(b)

Fig. 7 Temperature distribution of airflow in the face when the worker was located in the control range 
of the fifth tracking air cooler: (a) temperature contour; (b) variation of the temperature with the $X$ axis

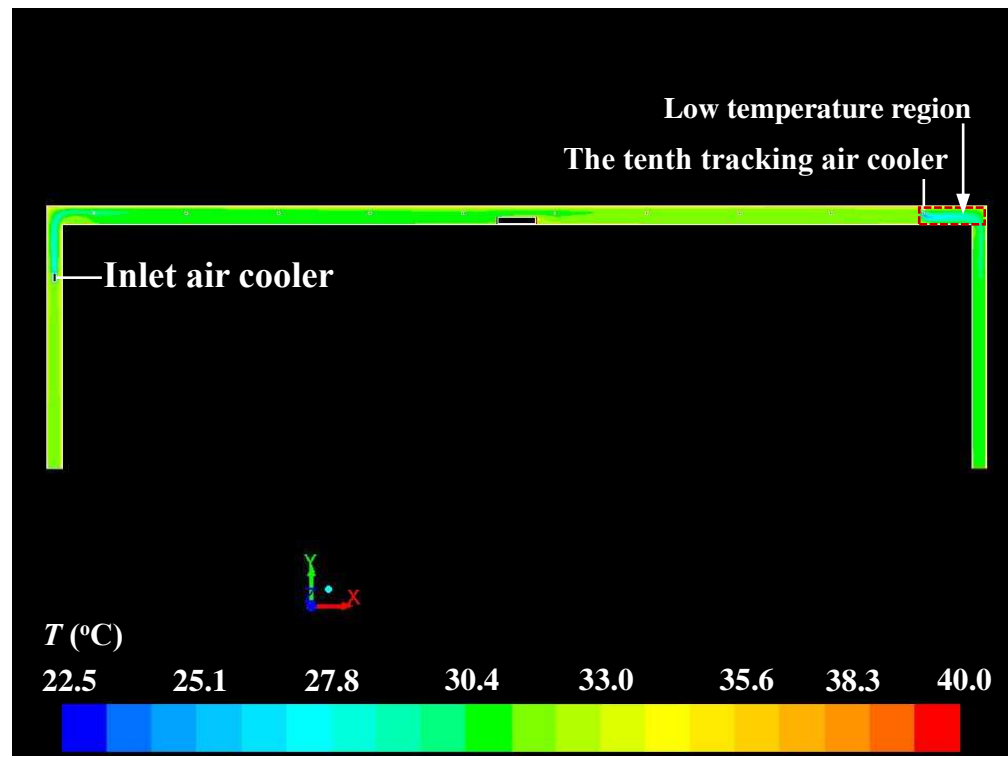

(a)

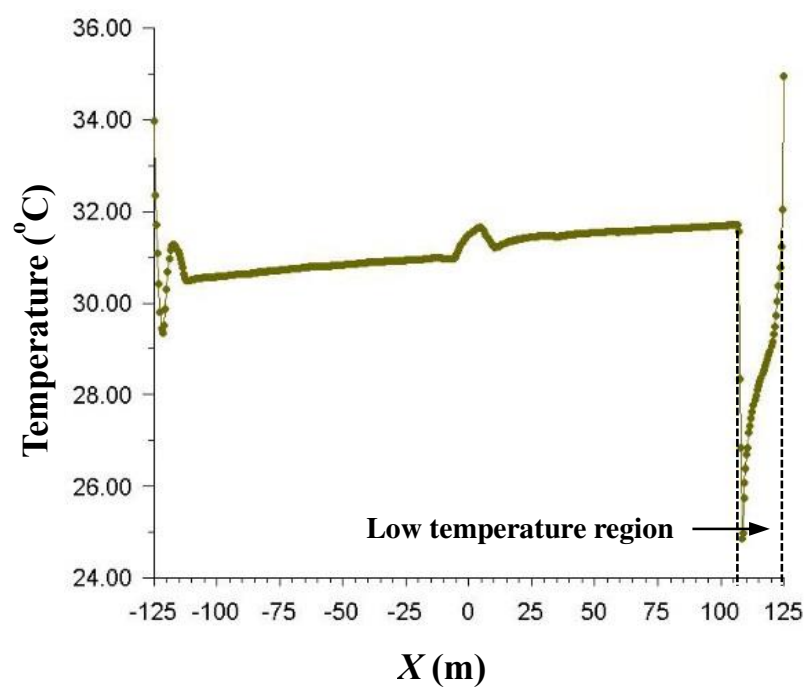

(b)

Fig. 8 Temperature distribution of airflow in the face when the worker was located in the control range of the tenth tracking air cooler: (a) temperature contour; (b) variation of the temperature with the $X$ axis

\section{Discussion}

\subsection{Main findings of this study}

This study proposed to build a non-homogeneous environment for high effective cooling in the mine 
face. The results revealed that this new cooling strategy could save a great amount of energy for cooling and significantly improve the thermal environment for the workers. Although some previous studies reported plenty of cooling strategies, no prior published literatures have considered to focus on the area occupied by workers and ignore the ineffective area in the face (Crawford et al. 2019; Guo and Chen 2013; Abdelaziz et al. 2011). A great amount of energy for cooling was ineffective. This new cooling strategy would be of help for energy efficiency and cooling effect improvement for mine cooling.

The concept of effective air-cooling space was proposed in this study. Since the mainly purpose of mining cooling was to ensure personnel safety, the area occupied by workers was critical for cooling. In contrast, the ineffective air-cooling space where no worker was could be ignored. After differentiating the effective and ineffective air-cooling spaces, it was helpful to determine the cooling range of the face and estimate the cooling load.

\subsection{Limitation of the current study and outline of future research}

For this new cooling strategy, the tracking cooler was designed to lay out in the mine face. However, this layout mode was restricted by many conditions such as space, dust, mechanical damage and pipeline laying (Li and Fu 2020). Dust could reduce the cooling effect of the air cooler. As warm air contacted with the coils of the heat exchanger, water film formed on its surface. This water film increased the adhesive of dust on the coils. After run for a long time, the surface of the heat exchanger might be deposited by plenty of dust particles and the performance decreased. In addition, the mine face was constantly moved and the tracking air cooler was also moved following the face. The removability of the tracking air cooler and the matched pipeline should be well designed. Further efforts are required to construct the tracking air cooler and test the practical application effect for the new cooling strategy.

For simplification, this study only conducted the case when the worker was face to the tracking air cooler and the air cooler did not rotated. When a worker moved, the air cooler rotated and tracked with him so that the air door was kept facing to the worker. The distance between the air cooler and the worker was longer than that when the worker was face to the air cooler. Because of the heat exchange between the cold air from the air cooler and the high temperature airflow in the face, the airflow temperature at 
the location of the worker was higher than that when the worker was face to the tracking air cooler. This investigation did not consider the above variations. More dedications are required to clarify the above issues.

\section{Conclusions}

This paper proposed to build a non-homogeneous environment for high effective cooling in the mine face. The tracking air cooler was designed to track the worker for improving the thermal environment. The concept of effective air-cooling space was proposed to determine the cooling area for workers. The cooling load and air distribution for this new cooling strategy were investigated. A numerical simulation of the airflow in the face was performed to estimate the cooling effect. It was found that an average energy saving of approximately $35 \%$ could be achieved for this cooling strategy. The airflow temperature was still high when the face was cooled only by the inlet air cooler. When the tracking air cooler worked, the thermal environment of the effective air-cooling space within at least $10 \mathrm{~m}$ was significantly improved. The airflow temperature decreased approximately $4.5^{\circ} \mathrm{C}$ in the control range of the tracking air cooler compared to that cooled only by the inlet air cooler. This new cooling strategy should be considered in the mining cooling.

Acknowledgements This research did not receive any specific grant from funding agencies in the public, commercial, or not-for-profit sectors.

Authors Contributions The research carried out by Xian Li under the guidance of Houli Fu.

\section{Compliance with ethical standards}

Conflict of interest The authors declare that they have no conflict of interest.

\section{References}

Abdelaziz E, Saidur R, Mekhilef S (2011) A review on energy saving strategies in industrial sector. 
Renew Sust Energ Rev 15:150-68.

Armstrong LE, Lopez RM (2007) Return to exercise training after heat exhaustion. J Sport Rehab 16:1829.

Bao HS, Wang YD, Roskilly AP (2014) Modelling of a chemisorption refrigeration and power cogeneration system. Appl Energy 119:351-62.

Bellas I, Tassou SA (2005) Present and future applications of ice slurries. Int J Refrig 28:115-21.

Chatterjee A, Zhang L, Xia X (2015) Optimization of mine ventilation fan speeds according to ventilation on demand and time of use tariff. Appl Energy 146:65-73.

Chen W, Liang SQ, Liu J (2016) Proposed split-type vapor compression refrigerator for heat hazard control in deep mines. Appl Therm Eng 105:425-35.

Crawford JA, Joubert HPR, Mathews MJ, Kleingeld M (2019) Optimised dynamic control philosophy for improved performance of mine cooling systems. Appl Therm Eng 150:50-60.

Du Plessis GE, Liebenberg L, Mathews EH (2013a) Case study: The effects of a variable flow energy saving strategy on a deep-mine cooling system. Appl Energy 102:700-9.

Du Plessis GE, Liebenberg L, Mathews EH (2013b) The use of variable speed drives for cost-effective energy savings in South African mine cooling systems. Appl Energy 111:16-27.

Guo HX, Zhu KJ, Ding C, Li LL (2010) Intelligent optimization for project scheduling of the first mining face in coal mining. Expert Syst Appl 37:1294-301.

Guo P, Chen C (2013) Field experimental study on the cooling effect of mine cooling system acquiring cold source from return air. Int J Min Sci Technol 23:453-6.

Guo P , Zhu G , He M (2014) HEMS technique for heat-harm control and geo-thermal utilization in deep mines. Int J Coal Sci Technol 3:289-296.

Hartman HL, Mutmansky JM, Ramani RV, Wang Y (2012) Mine ventilation and air conditioning. California: John Wiley \& Sons.

Homer AW (2009) Coal mine safety regulation in China and the USA. J Contemp Asia 39:424-39.

Ji J, Li N, Chang Z, Fan Y, Ni L (2019) Study on heat transfer characteristic parameters and cooling effect of cold wall cooling system in coal mines. Exp Heat Transfer 33:1-18.

Kasap Y (2011) The effect of work accidents on the efficiency of production in the coal sector. S Afr J Sci 107:77-85.

Katavoutas G, Assimakopoulos MN, Asimakopoulos DN (2016) On the determination of the thermal 
comfort conditions of a metropolitan city underground railway. Sci Total Environ 566:877-87.

Kusiak A, Li MY (2010) Cooling output optimization of an air handling unit. Appl Energy 87:901-9.

Li X, Fu H (2020) Development of an efficient cooling strategy in the heading face of underground mines.

Energies 13(5): 1116.

Maurya T, Karena K, Vardhan H, Aruna M, Raj MG (2015) Effect of heat on underground mine workers.

Procedia Earth Planet Sci 11:491-8.

Sasmito AP, Kurnia JC, Birgersson E, Mujumdar AS (2015) Computational evaluation of thermal management strategies in an underground mine. Appl Therm Eng 90:1144-50.

Su Z, Jiang Z, Sun Z (2009) Study on the heat hazard of deep exploitation in high-temperature mines and its evaluation index. Procedia Earth Planet Sci 1:414-9.

Waltrich M, Hermes CJL, Melo C (2011) Simulation-based design and optimization of refrigeration cassettes. Appl Energy 88:4756-65.

Wang S, Jin L, Han Z, Li Y, Ou S, Gao N, et al (2017) Discharging performance of a forced-circulation ice thermal storage system for a permanent refuge chamber in an underground mine. Appl Therm Eng 110:703-9.

Yi X, Ren L, Ma L, Wei G, Yu W, Deng J, et al (2019). Effects of seasonal air temperature variation on airflow and surrounding rock temperature of mines. Int J Coal Sci Technol 6(3): 388-398. 
Figures

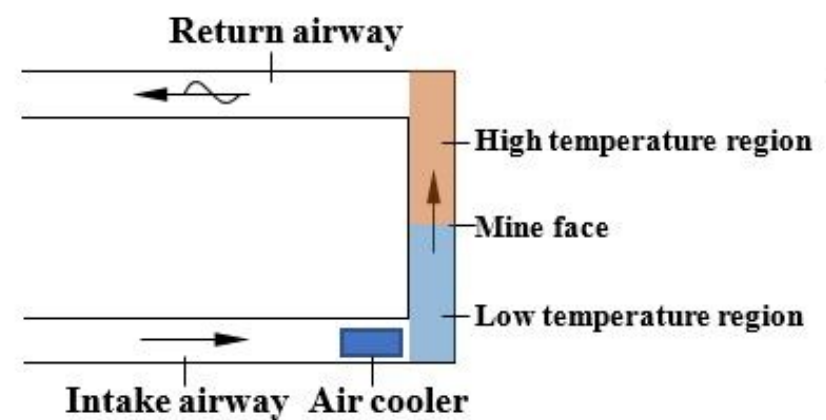

(a)

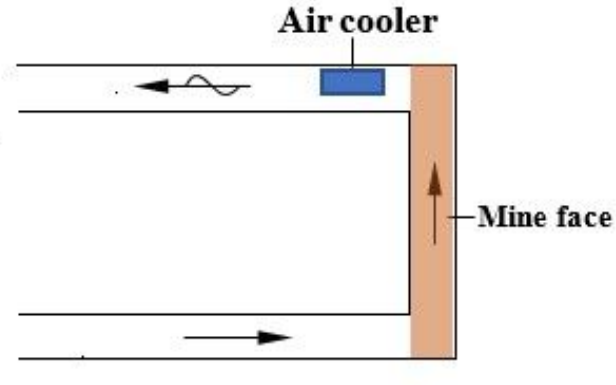

(b)

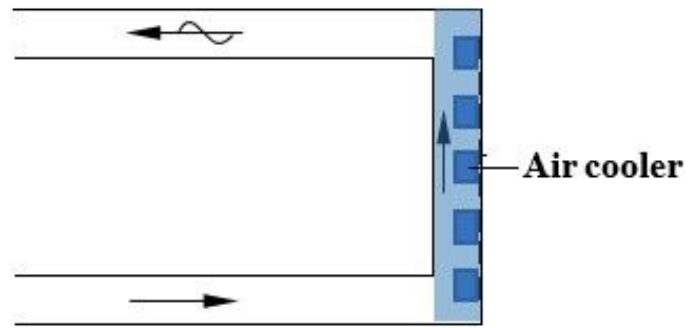

(c)

\section{Figure 1}

Layout mode of the air cooler for mine cooling at various locations: (a) intake airway; (b) return airway; (c) mine face 


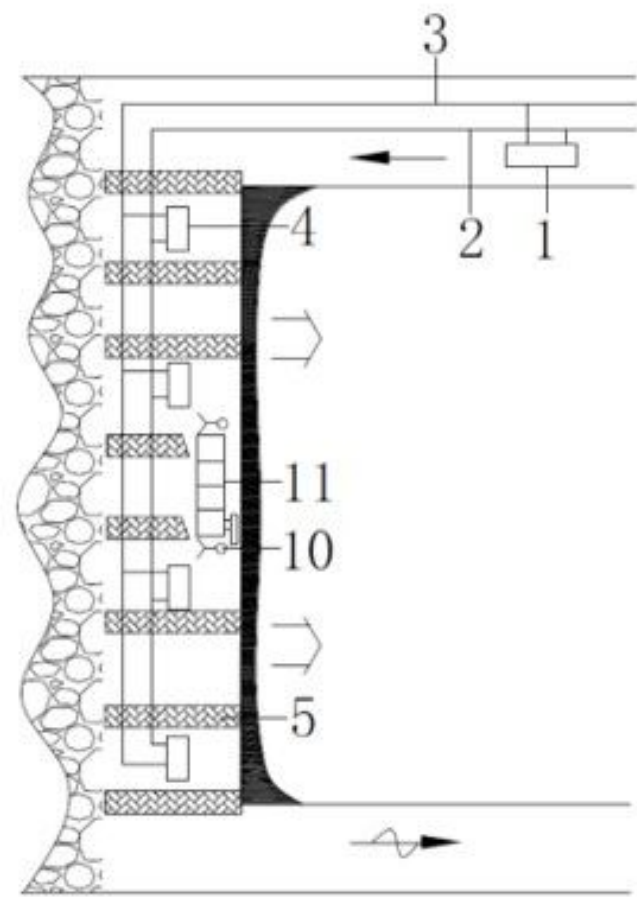

(a)

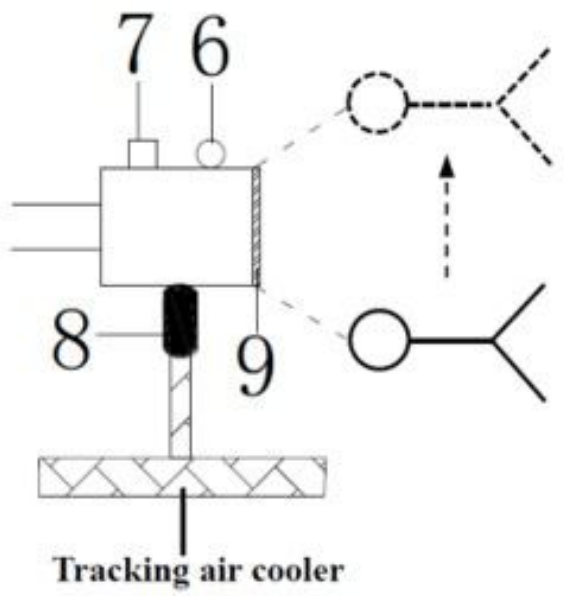

(b)

1. Inlet air cooler, 2. Inlet pipe of the chilled water, 3. Return pipe of the cooling water, 4 . Tacking small air cooler, 5. Hydraulic support, 6. Infrared detector, 7. Controller, 8. Electric spindle, 9. Air door, 10. Worker, 11. Shearer

\section{Figure 2}

Schematic diagram of building the non-homogeneous environment in the face: (a) layout mode of the inlet and tracking air coolers; (b) constitution of the tracking air cooler

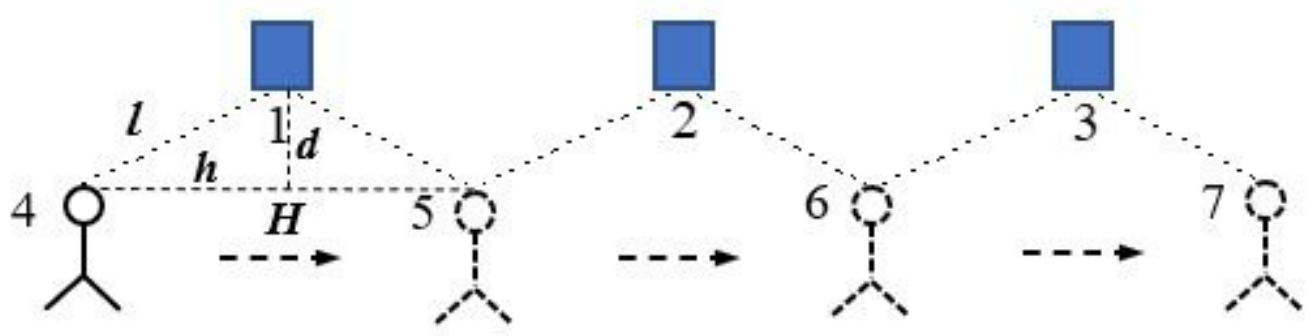

\section{Figure 3}

Schematic diagram of cooling process of the tracking air cooler 


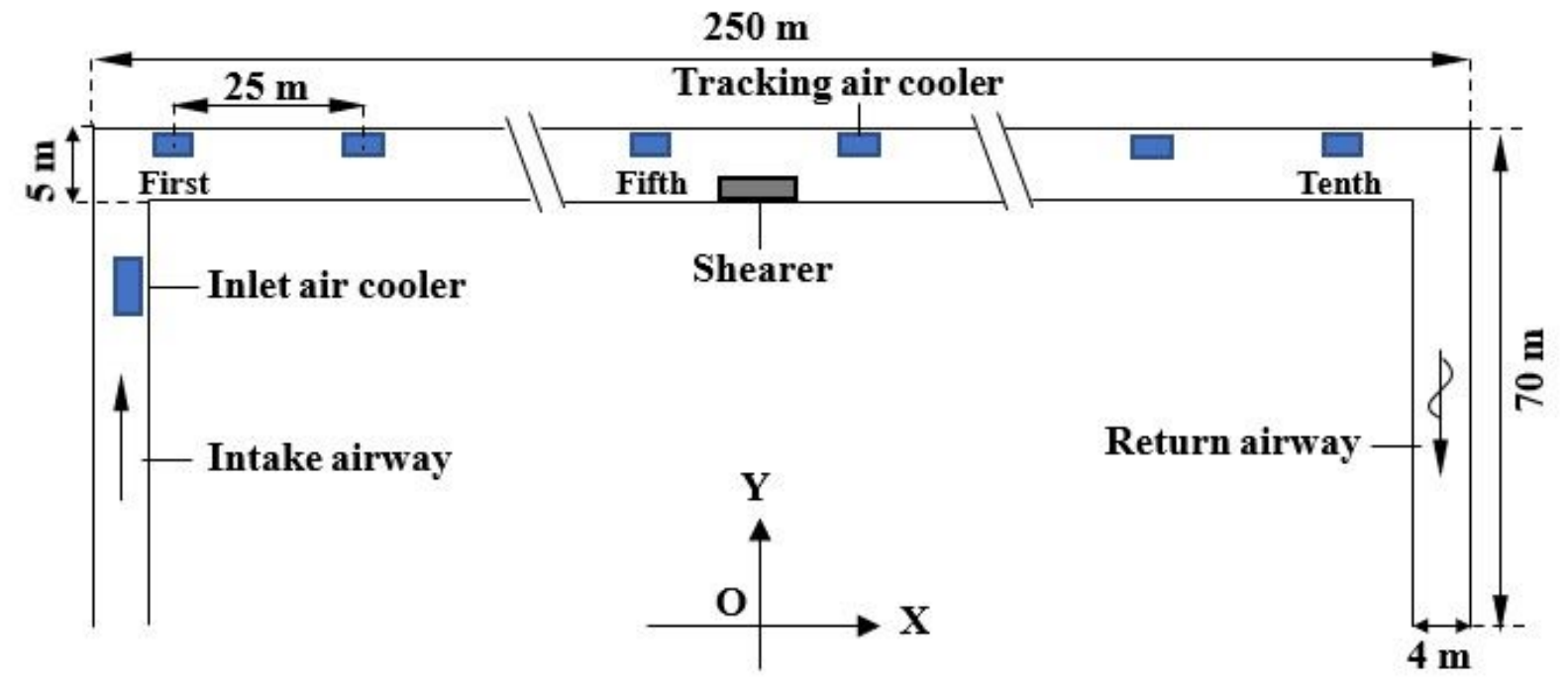

Figure 4

Geometric model of the mine face for CFD simulations

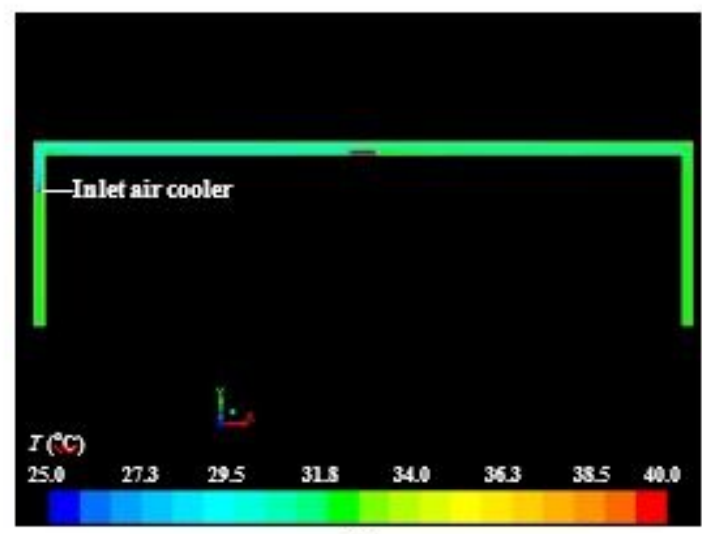

(a)

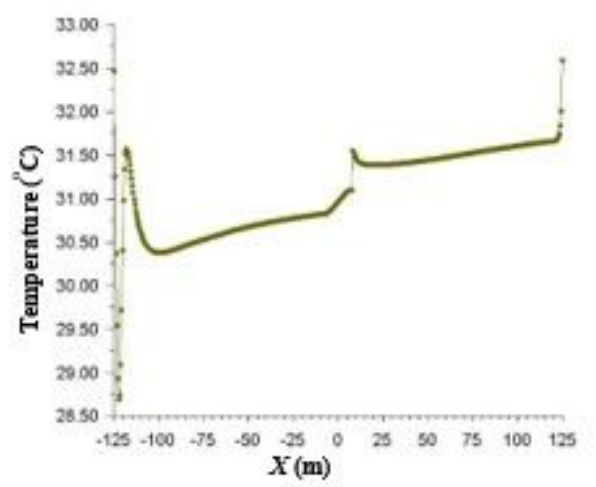

(b)

\section{Figure 5}

Temperature distribution of airflow in the face cooled only by the inlet air cooler: (a) temperature contour; (b) variation of the temperature with the $X$ axis 


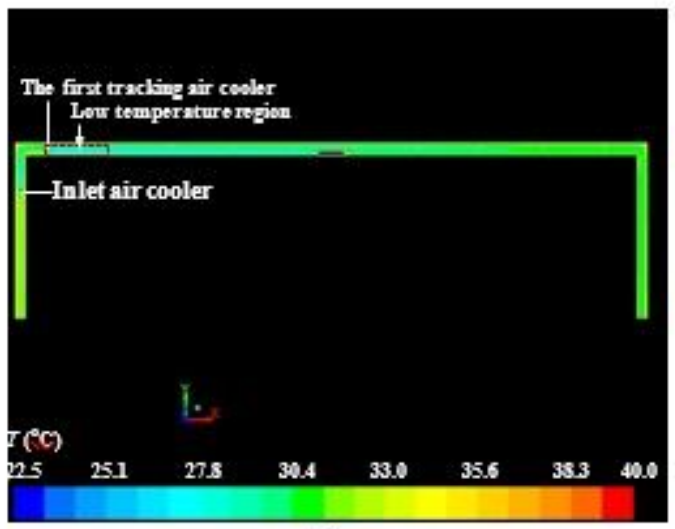

(a)

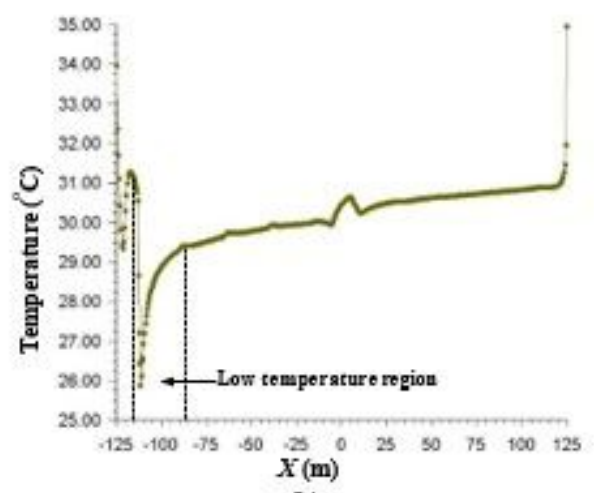

(b)

\section{Figure 6}

Temperature distribution of airflow in the face when the worker was located in the control range of the first tracking air cooler: (a) temperature contour; (b) variation of the temperature with the $\mathrm{X}$ axis 


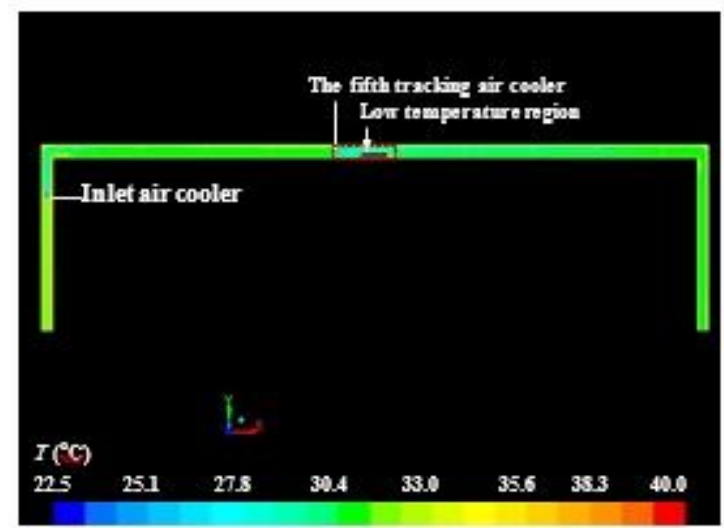

(a)

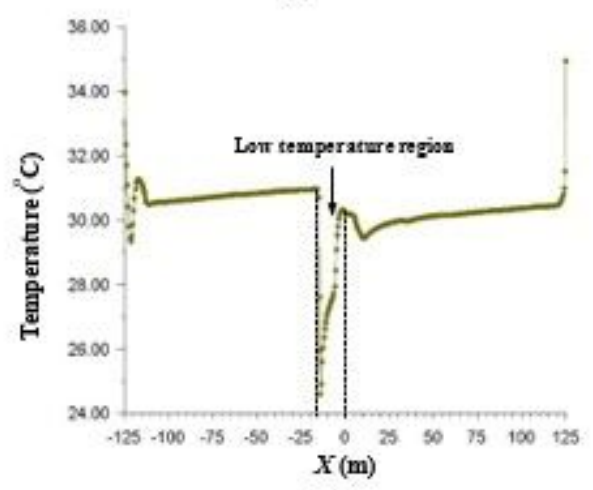

(b)

Figure 7

Temperature distribution of airflow in the face when the worker was located in the control range of the fifth tracking air cooler: (a) temperature contour; (b) variation of the temperature with the $\mathrm{X}$ axis 


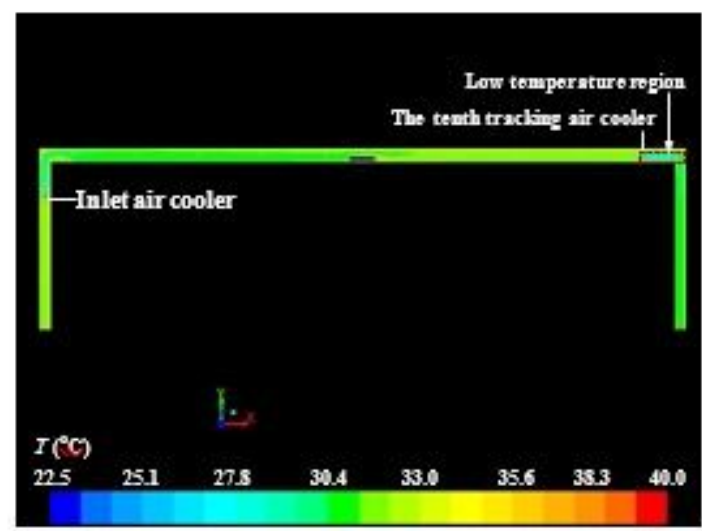

(a)

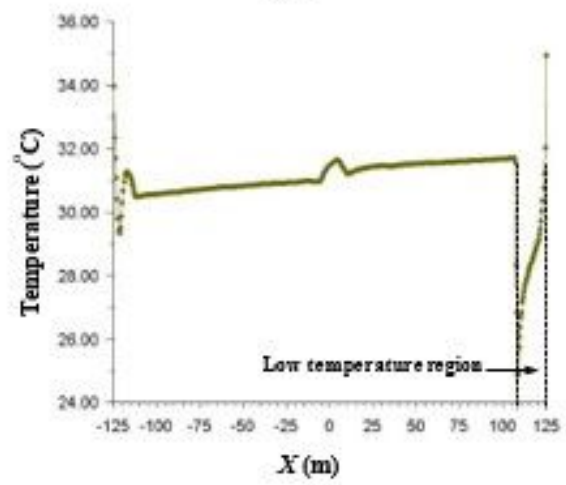

(b)

\section{Figure 8}

Temperature distribution of airflow in the face when the worker was located in the control range of the tenth tracking air cooler: (a) temperature contour; (b) variation of the temperature with the $\mathrm{X}$ axis 